\title{
Identification of 2-(\{[1-(4-fluorophenyl)-5-(2- methoxyphenyl)-1H-pyrazol-3-
}

\section{yl]carbonyl\}amino)tricyclo[3.3.1.13,7]decane-2- carboxylic acid (NTRC-844) as a selective}

antagonist for the Rat Neurotensin receptor type 2

James B. Thomas ${ }^{a}{ }^{*}$, Mélanie Vivancos ${ }^{b}$, Angela M. Giddings ${ }^{a}$, Robert W. Wiethe ${ }^{a}$, Keith R. Warner $^{a}$, Alexandre Murza ${ }^{b}$, Élie Besserer-Offroy ${ }^{b}$, Jean-Michel Longpré $e^{b}$, Scott P. Runyon ${ }^{a}$, Brian P. Gilmour ${ }^{a}$, and Philippe Sarret ${ }^{b}$

${ }^{a}$ Center for Drug Discovery, RTI International, P. O. Box 12194, Research Triangle Park, North Carolina 27709, United States

${ }^{b}$ Department of Pharmacology and Physiology, Faculty of Medicine and Health Sciences, Université de Sherbrooke, 3001, 12th Ave. North, Sherbrooke, QC, J1H 5N4, Canada

Supplemental Information 


\begin{tabular}{|c|c|c|c|c|c|c|c|}
\hline \multirow{2}{*}{ Compd } & \multirow{2}{*}{ formula } & \multicolumn{3}{|c|}{ Calculated } & \multicolumn{3}{c|}{ Found } \\
\cline { 3 - 8 } & & $\mathrm{C}$ & $\mathrm{H}$ & $\mathrm{N}$ & $\mathrm{C}$ & $\mathrm{H}$ & $\mathrm{N}$ \\
\hline $\mathbf{8}$ & $\mathrm{C}_{28} \mathrm{H}_{28} \mathrm{FN}_{3} \mathrm{O}_{4}$ & 68.70 & 5.77 & 8.58 & 68.88 & 5.62 & 8.21 \\
\hline
\end{tabular}

${ }^{13} \mathrm{C}$ NMR for compound 8: ${ }^{13} \mathrm{C}$ NMR $\left(75 \mathrm{~Hz}, \mathrm{CDCl}_{3}\right) \delta 172.8,163.8,163.4,160.2,156.4,145.6$, $142.5,136.5,136.5,131.2,131.2,125.8,125.7,120.9,118.6,115.7,115.4,111.3,109.4,77.4$, $77.2,77.0,76.6,65.2,54.9,37.5,33.7,32.6,32.2,26.7,26.6$

${ }^{19} \mathrm{~F}$ NMR for Compound 8: ${ }^{19} \mathrm{~F}$ NMR $\left(282 \mathrm{MHz}, \mathrm{CDCl}_{3}\right) \delta-\square \square \square \square \square \square$.

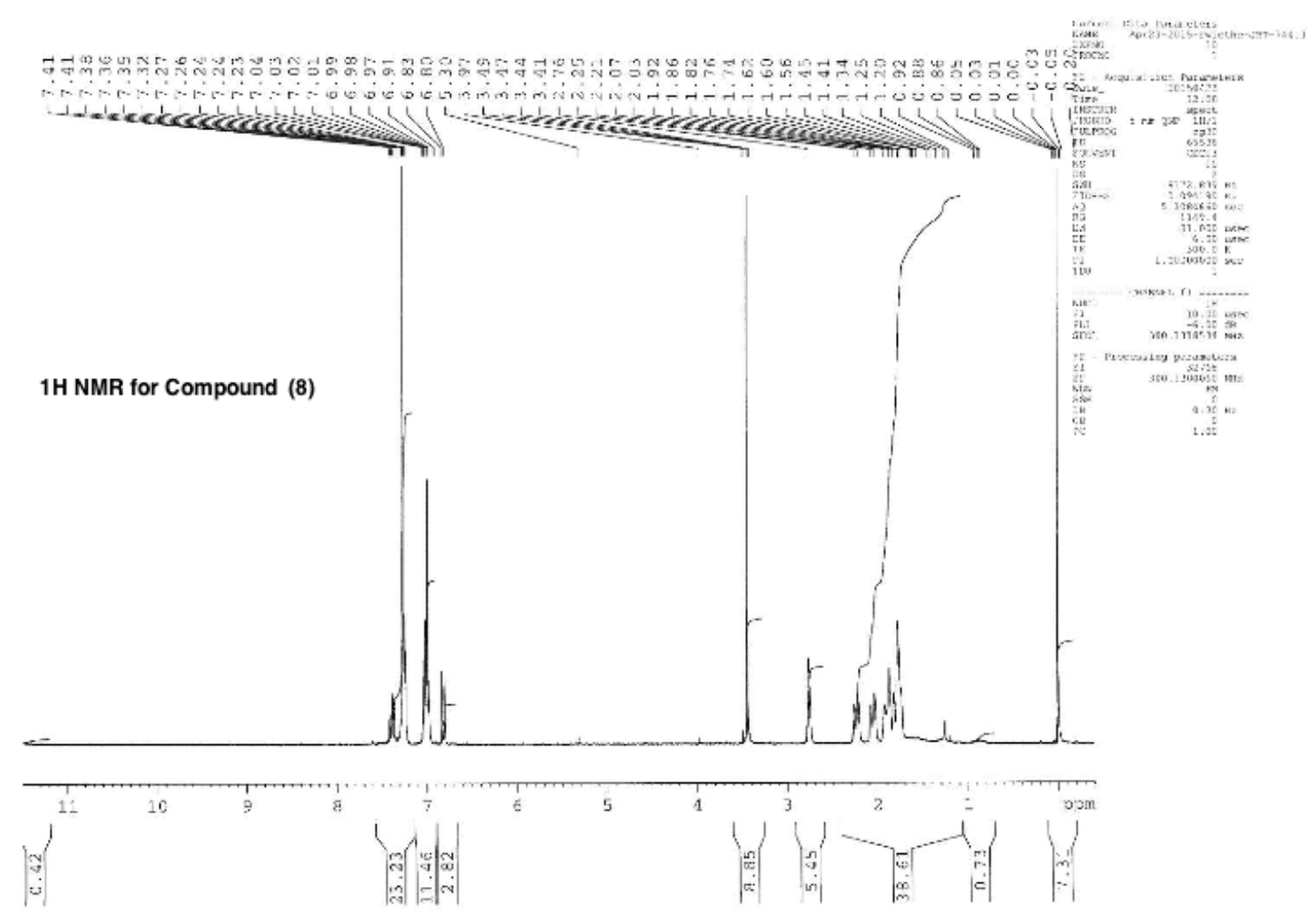




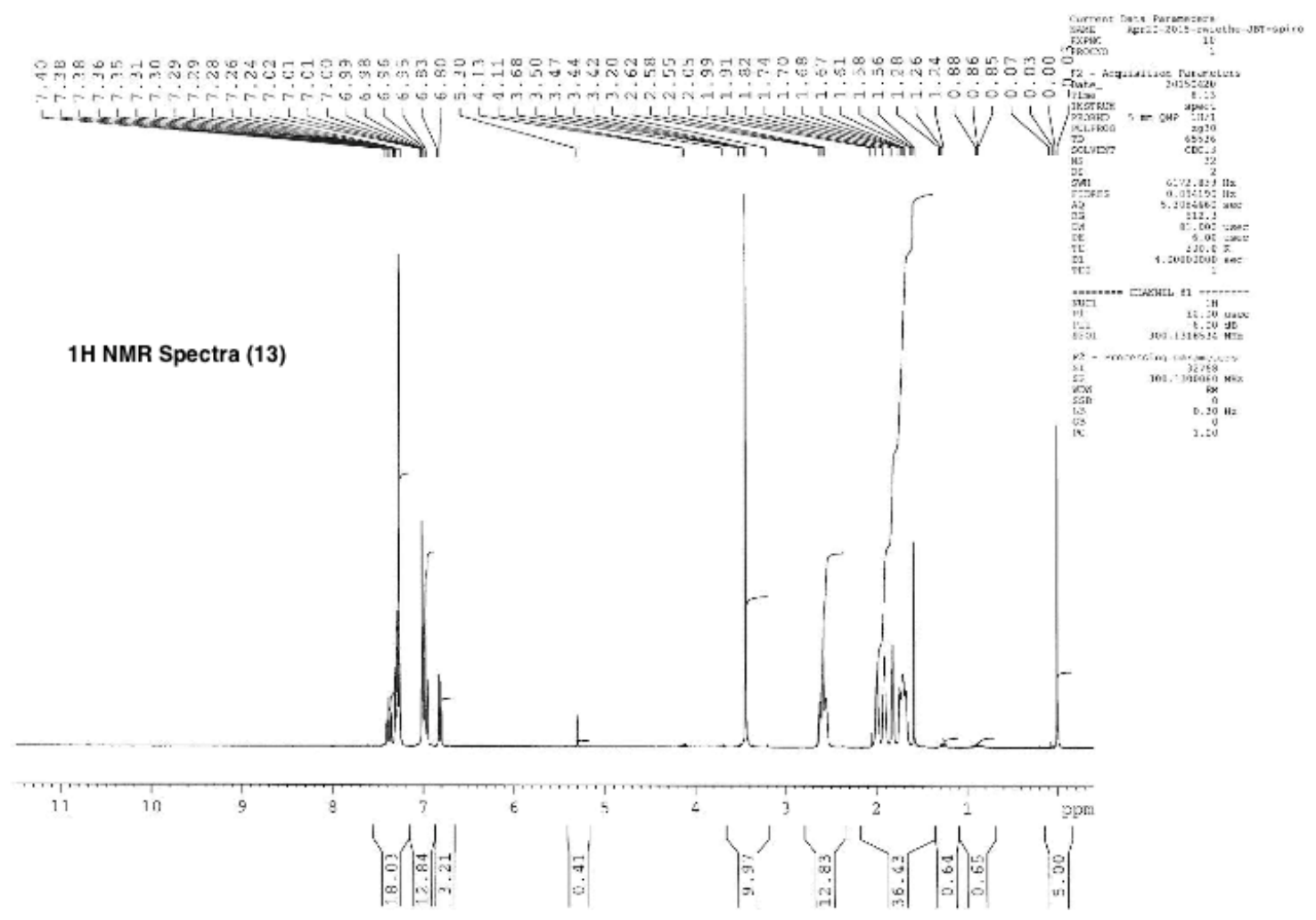




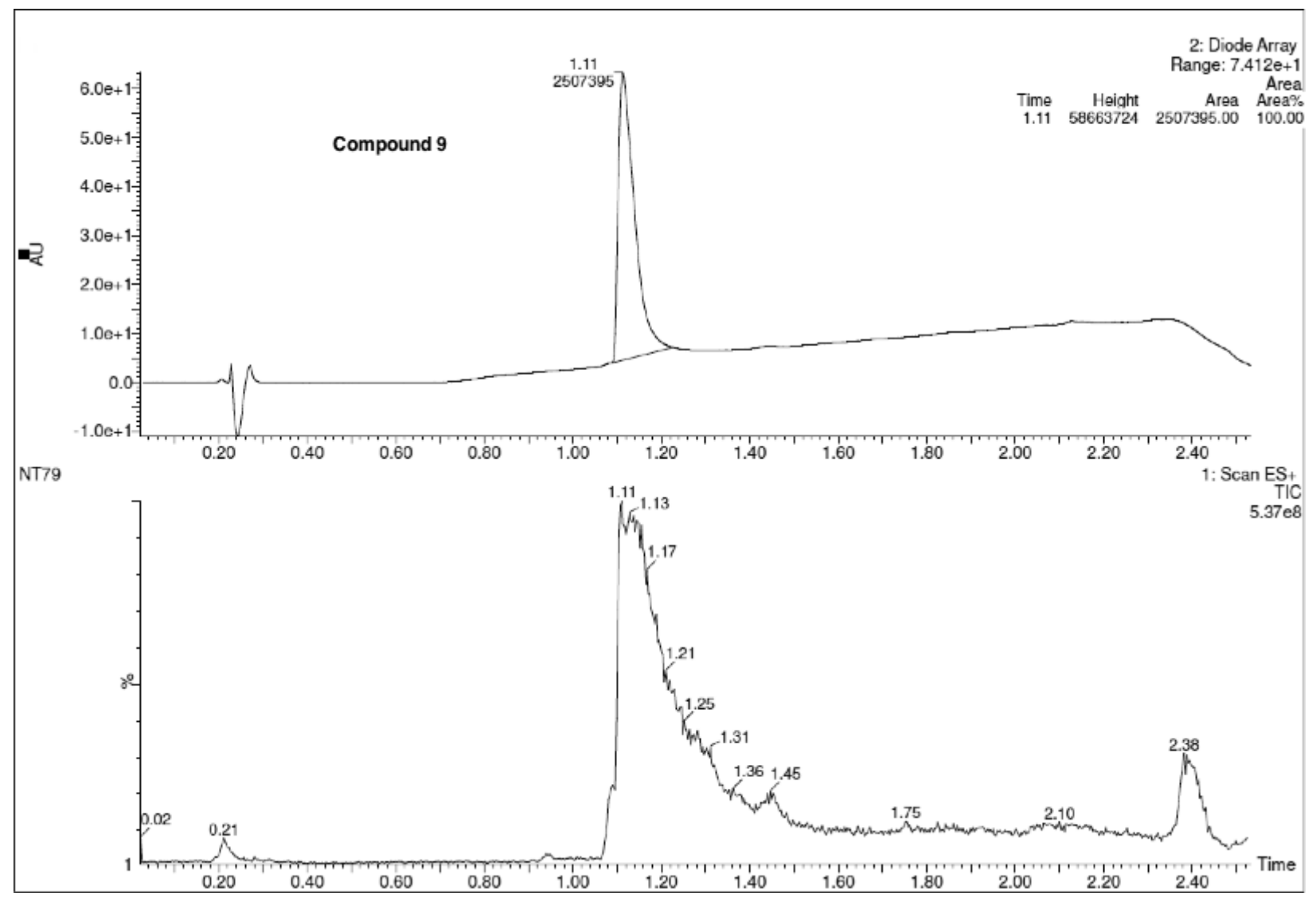




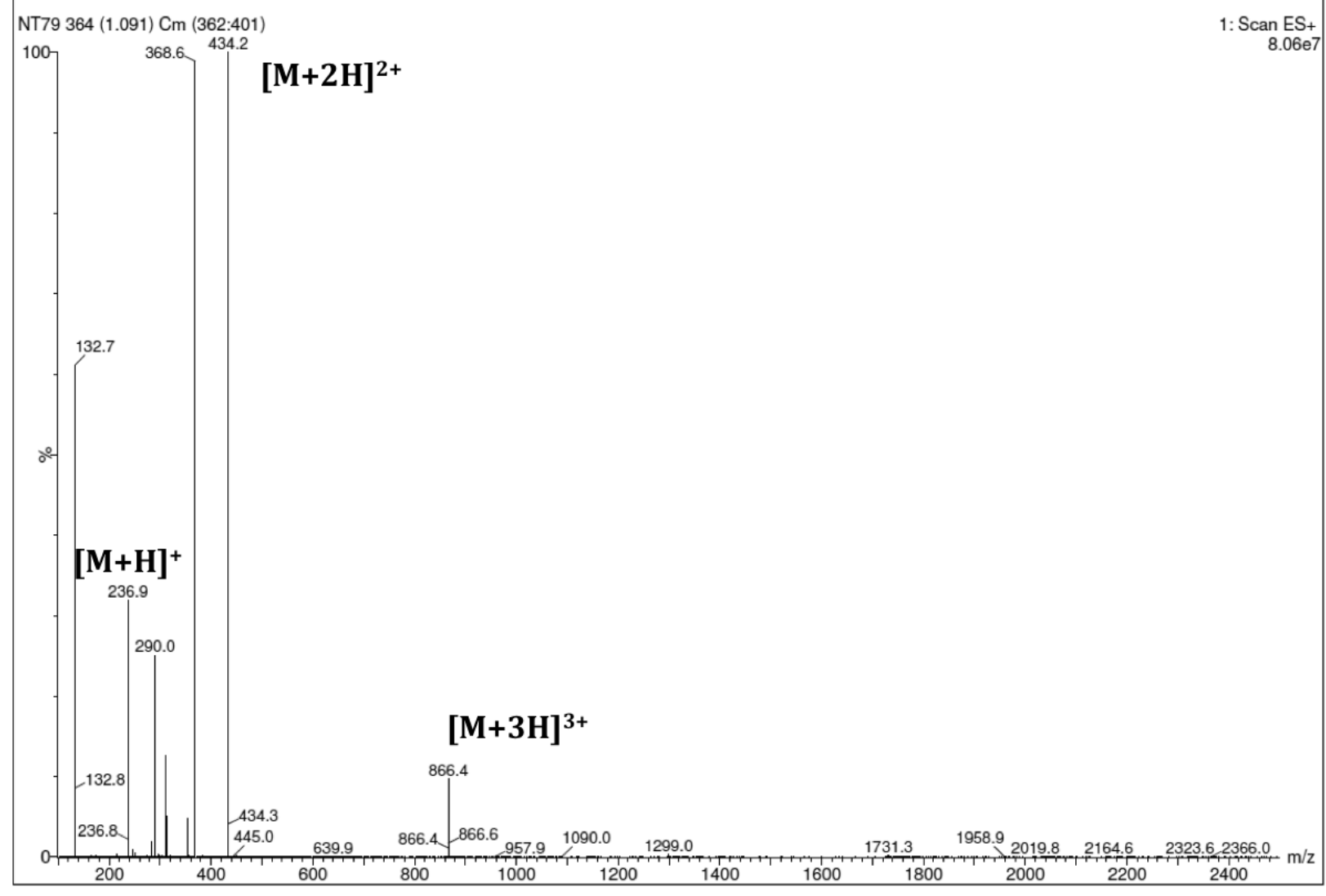

